\title{
Long term monitoring in patients receiving treatment to lower blood pressure: analysis of data from placebo controlled randomised controlled trial
}

\author{
Katherine Keenan, general practitioner, ${ }^{1}$ Andrew Hayen, senior lecturer in biostatistics, ${ }^{1}$ Bruce C Neal, \\ professor of medicine, ${ }^{2}$ Les Irwig, professor of epidemiology ${ }^{1}$
}

${ }^{1}$ Screening and Test Evaluation Program (STEP), School of Public Health, Building A27, University of Sydney, New South Wales 2006, Australia

${ }^{2}$ George Institute for International Health, Royal Prince Alfred Hospital, Building C39, University of Sydney, New South Wales

Correspondence to: A Hayen ahayen@health.usyd.edu.au

Cite this as: $B M J$ 2009;338:b1492 doi:10.1136/bmj.b1492

\section{ABSTRACT}

Objective To determine the value of monitoring blood pressure by quantifying the probability that observed changes in blood pressure reflect true changes.

Design Analysis of blood pressure measurements of patients in the perindopril protection against recurrent stroke study (PROGRESS).

Setting Randomised placebo controlled trial carried out in 172 centres in Asia, Australasia, and Europe.

Participants 1709 patients with history of stroke or transient ischaemic attack randomised to fixed doses of perindopril and indapamide.

Measurements Mean of two blood pressure measurements in patients receiving treatment recorded to the nearest $2 \mathrm{~mm} \mathrm{Hg}$ with a standard mercury sphygmomanometer at baseline and then at three months, six months, nine months, and 15 months and then every six months to 33 months.

Results There was no change in the mean blood pressure of the cohort during the 33 month follow-up. Six months after blood pressure was stabilised on treatment, if systolic blood pressure was measured as having increased by $>10 \mathrm{~mm} \mathrm{Hg}$, six of those measurements would be false positives for every true increase of $\geq 10 \mathrm{~mm}$ $\mathrm{Hg}$. The corresponding value for an increase of $20 \mathrm{~mm} \mathrm{Hg}$ was over 200. Values for $5 \mathrm{~mm} \mathrm{Hg}$ and $10 \mathrm{~mm} \mathrm{Hg}$ increases in diastolic blood pressure were 3.5 and 39 , respectively. The likelihood that observed increases in blood pressure reflected true increases rose with the time between measurements such that the ratio of true positives to false positives reached parity at 21 months. Conclusions Usual clinical approaches to the monitoring of patients taking drugs to lower blood pressure have a low probability of yielding reliable information about true changes in blood pressure. Evidence based guidelines for monitoring treatment response are urgently required to guide clinical practice.

Trial registration Australia and New Zealand Clinical Trial Registry.

\section{INTRODUCTION}

The size of the reduction in blood pressure achieved with antihypertensive drugs is key to the protection afforded by these agents. ${ }^{1}$ Clinicians commonly monitor the response of blood pressure to treatment ${ }^{2}$ to ensure maximum benefit for each individual. They typically monitor their patients' blood pressure shortly after initiation of treatment and then continue monitoring for the long term. Monitoring strategies are based on the assumption that measured blood pressure can be used to reliably identify the adequacy or inadequacy of treatment. Measurements of blood pressure, however, are rather imprecise because they are prone to considerable background day to day variability ("noise") and this can make it difficult to detect a true change in blood pressure ("signal"). To be effective, long term monitoring requires the correct interpretation of measurements as reflecting either noise or signal. If the impact of noise is not fully appreciated then the effectiveness of treatments might be wrongly interpreted, resulting in under or over-treatment. ${ }^{3-6}$

Patients established on blood pressure lowering drugs are monitored long term in anticipation of an increase in blood pressure in subsequent years. Monitoring is used to detect a rise in blood pressure above a certain threshold level (typically $140 / 90 \mathrm{~mm} \mathrm{Hg}$ ) that acts as a signal warranting re-measurement or adjustment of treatment. While an average increase in population blood pressure over time is well established, there is probably substantial variability in the size of the increase between individuals. This variability is expected to increase over time and, therefore, longer time intervals between measurements might increase the effectiveness of monitoring.

Patients on fixed doses of antihypertensive drugs, such as those in the treatment arms of randomised trials, provide an opportunity to examine to what extent the observed variability in blood pressure measurements in treated patients is caused by true changes in blood pressure. We studied the treatment arm of the perindopril protection against recurrent stroke study (PROGRESS) to examine how variability in blood pressure changes over time and its possible impact on monitoring strategies. We estimated the proportion of patients who would be correctly identified as having 


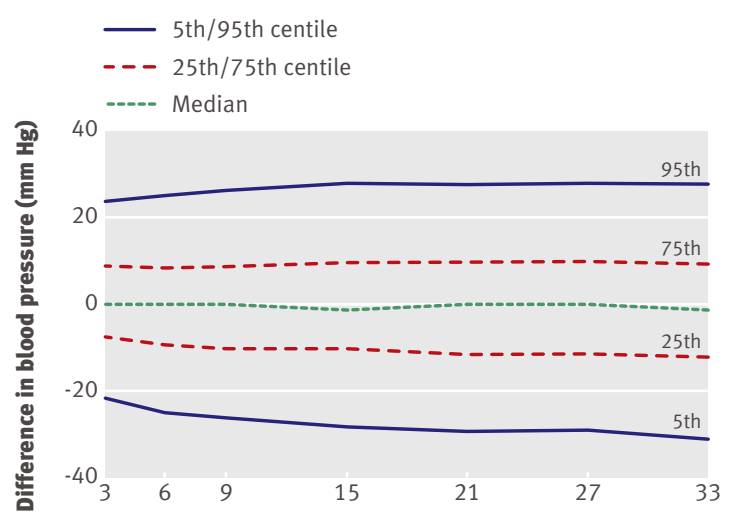

Time from baseline measurement (months)

Fig 1| Difference in systolic blood pressure $(\mathrm{mm} \mathrm{Hg})$ from baseline measurement to subsequent measurements over time to 33 months in those receiving dual treatment

truly exceeded blood pressure thresholds for monitoring intervals of three to 33 months.

\section{METHODS}

Details of the PROGRESS trial have been described previously. ${ }^{7}$ We analysed the dual treatment arm, for which active treatment was a regimen of perindopril $4 \mathrm{mg}$ and indapamide $2.0-2.5 \mathrm{mg}$ daily, using data from the visit at three months after randomisation until the three year visit. We restricted analyses to the active treatment arm because our objective was to assess long term variability after starting blood pressure lowering treatment. At each visit, recorded blood pressure was the mean of two measurements taken five minutes apart with the patient in the seated position, with each measurement being recorded to the nearest $2 \mathrm{~mm} \mathrm{Hg}$ with a standard mercury sphygmomanometer. For the purpose of this analysis, the three month visit after randomisation was fixed as the time at which a patient will have achieved a reduction in blood pressure as a result of antihypertensive treatment and the time at which long term monitoring is initiated. We estimated long term change in blood pressure from this baseline measurement from the difference between it and the subsequent follow-up "observed" blood

Table 1 |Characteristics of participants randomised to dual treatment for hypertension

\begin{tabular}{|c|c|c|}
\hline & $\begin{array}{l}\text { After start of treatment } \\
\text { (baseline) }(n=1709)\end{array}$ & $\begin{array}{l}\text { Before start of treatment } \\
\qquad(n=1770)\end{array}$ \\
\hline Mean (SD) age (years) & $63(9)$ & $63(9)$ \\
\hline No (\%) of men & $1205(71)$ & $1243(70)$ \\
\hline \multicolumn{3}{|l|}{ Mean (SD) blood pressure $(\mathrm{mm} \mathrm{Hg})$ : } \\
\hline Systolic & $133(17)$ & $149(18)$ \\
\hline Diastolic & $80(10)$ & $87(11)$ \\
\hline No (\%) with hypertension* & $341(20)$ & $948(54)$ \\
\hline $\begin{array}{l}\text { No (\%) taking other antihypertensive } \\
\text { drugt }\end{array}$ & $678(41) \ddagger$ & $1009(57)$ \\
\hline
\end{tabular}

pressure measurements at each time point (three months, six months, nine months, etc).

The observed blood pressure at each follow-up point comprises an underlying "true" average blood pressure plus the "short term variability" caused by technical measurement error and short term biological fluctuations (often called "within person" variability or simply "measurement error"). We use the term short term variability to describe fluctuations in blood pressure over a short time period (such as a few days or a week ${ }^{5}$ ). Short term variance is the statistical measure of short term variability. Squaring the standard deviation (SD) gives the "variance," which is an additive measure convenient for calculating changes in variability. Short term variability is part of each followup measurement - that is,

[observed follow-up blood pressure] $=$ [true blood pressure] + [short term variability].

The short term variance can be estimated by halving the observed variance of the difference between two measurements made within a short time interval. As a first approximation, we obtained the short term variance from the difference between the measurements at six and three months. Because the three month time delay might incorporate some true long term change, however, we ultimately estimated the expected short term variance using the variogram approach ${ }^{8}$ (see appendix 1 on bmj.com).

Observed long term changes in blood pressure will incorporate the "true" average change in the blood pressure, twice the short term variability (once for the initial measurement and once for the subsequent measurement), and the "long term variability"- that is, [observed change in blood pressure from baseline] = [true average change in blood pressure] +

[2 x (short term variability) + (long term variability)]. The long term variability is the "between person" variability caused by individuals' long term changes in blood pressure deviating above or below the average change of the group. The long term variance can be estimated from the total observed variance of the difference in blood pressure measurements from the baseline to each subsequent time point. The above equation shows that subtracting twice the short term variance from the total observed variance of the change will give an estimate of the long term variance (see appendix 1 on bmj.com).

Using the calculated change in variance at each time point, we estimated the proportion of patients whose assumed true baseline systolic blood pressure of 130 or $120 \mathrm{~mm} \mathrm{Hg}$ would truly increase by 10 or $20 \mathrm{~mm} \mathrm{Hg}$ (called true positives) to a threshold of $140 \mathrm{~mm} \mathrm{Hg}$ or above while receiving treatment. We also estimated the proportion of patients who would be observed to be above the thresholds but who actually had true blood pressure levels below the threshold (that is, false positives). We repeated this for an assumed true baseline diastolic blood pressure of 85 or $80 \mathrm{~mm} \mathrm{Hg}$ and used changes in blood pressure of 5 or $10 \mathrm{~mm} \mathrm{Hg}$ to reach a threshold of $90 \mathrm{~mm} \mathrm{Hg}$ or above. For both 


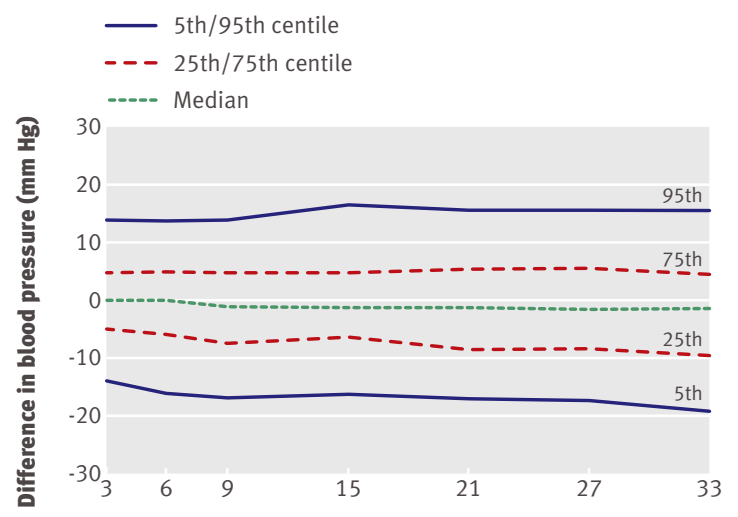

Time from baseline measurement (months)

Fig 2 Difference in diastolic blood pressure $(\mathrm{mm} \mathrm{Hg})$ from baseline measurement to subsequent measurements over time to 33 months in those receiving dual treatment

systolic and diastolic blood pressure we estimated these assuming no change in mean blood pressure over the three year period. In sensitivity analyses we also estimated the true and false positive probabilities assuming an average $1.0 \mathrm{~mm} \mathrm{Hg}$ per year increase in systolic blood pressure and a $0.5 \mathrm{~mm} \mathrm{Hg}$ per year increase in diastolic blood pressure. ${ }^{9}$ The calculations assume that the baseline value and the true change with time are normally distributed and are independent of each other. See appendix 1 on bmj.com for full details of the methods.

Previous research has shown distributions of systolic blood pressure to be skewed to the right and variability to be correlated with blood pressure levels. ${ }^{510-13}$ Therefore, we checked the distributions of systolic and diastolic blood pressure for normality and examined Bland-Altman plots of the difference in the measurements from baseline to three months against the average of these two measurements. Use of a natural log transformation normalised distributions of systolic blood pressure and reduced the correlation between variability and blood pressure level, and we subsequently repeated analyses after natural log transformation of systolic blood pressure measurements.

Because the methods described above assume independence between baseline blood pressure and the true change from baseline blood pressure, we also repeated the analyses using an approach based on mixed models, which do not assume independence between baseline level and the true change from baseline level.

\section{RESULTS}

\section{Baseline characteristics}

Detailed characteristics of the participants at enrolment have been described previously, ${ }^{14}$ but table 1 summarises demographic and blood pressure characteristics relevant to this study. About 38\% $(n=1357)$ of patients at randomisation were recruited in Asian countries (China or Japan) and the remainder in Australasia and Europe. At three months after randomisation, blood pressure measurements were available for 1709 study participants receiving dual active treatment. At 33 months of follow-up, more than 93\% (1591) of these individuals had blood pressure measurements recorded.

At baseline visit (three months after randomisation to active combination treatment with an angiotensin converting enzyme (ACE) inhibitor and a diuretic) participants had an average systolic blood pressure of 133 (SD 17) $\mathrm{mm} \mathrm{Hg}$ and diastolic blood pressure of 80 (SD 10) $\mathrm{mm} \mathrm{Hg}$. Blood pressure had decreased on average $16 \mathrm{~mm} \mathrm{Hg}$ and $7 \mathrm{~mm} \mathrm{Hg}$, respectively, from that recorded before treatment started. Over half $(58 \%)$ of participants were prescribed an additional antihypertensive drug (in addition to perindopril and indapamide) at randomisation and $38 \%$ at three years' follow-up.

\section{Follow-up blood pressure and variability}

Systolic blood pressure-The mean blood pressure in the 1709 participants did not change substantially during follow-up (table 2). The variability of the difference from baseline increased over time, as shown by the increasing variance (table 2) and the distribution centiles (fig 1). The short term variance was estimated to be $93.3 \mathrm{~mm} \mathrm{Hg}^{2}$ (that is, $\mathrm{SD} 9.7 \mathrm{~mm} \mathrm{Hg}$ ). Long term variability increased over the 30 month interval from an SD of $3.8 \mathrm{~mm} \mathrm{Hg}$ at three months to $11.8 \mathrm{~mm} \mathrm{Hg}$ at 33 months. Appendix 2 on bmj.com shows comparable results for analyses based on the logarithm of systolic blood pressure.

Table 2 | Long term variability of systolic blood pressure for those receiving dual treatment, calculated from difference from on treatment baseline measurement of $133 \mathrm{~mm} \mathrm{Hg}$ (SD 17) to each subsequent time point

\begin{tabular}{|c|c|c|c|c|c|}
\hline \multirow[b]{2}{*}{ Time (months) } & \multirow[b]{2}{*}{ No of patients } & \multicolumn{2}{|c|}{ Difference from baseline $(\mathrm{mm} \mathrm{Hg})$} & \multirow{2}{*}{$\begin{array}{l}\text { Long term variance* } \\
\qquad\left(\mathrm{mm} \mathrm{Hg}^{2}\right)\end{array}$} & \multirow{2}{*}{$\begin{array}{l}\text { Long term SD } \dagger \\
\quad(\mathrm{mm} \mathrm{Hg})\end{array}$} \\
\hline & & Mean $(95 \% \mathrm{Cl})$ & Variance & & \\
\hline 3 & 1670 & 0.7 (0.01 to 1.37$)$ & 200.9 & 14.4 & 3.8 \\
\hline 6 & 1638 & $-0.3(-1.0$ to -0.5$)$ & 224.1 & 37.6 & 6.1 \\
\hline 9 & 1644 & $-0.9(-1.7$ to -0.08$)$ & 270.8 & 84.3 & 9.2 \\
\hline 15 & 1624 & $-0.4(-1.2$ to 0.4$)$ & 283.6 & 97.0 & 9.8 \\
\hline 21 & 1612 & $-0.7(-1.6$ to 0.1$)$ & 303.6 & 117.1 & 10.8 \\
\hline 27 & 1585 & $-0.2(-1.0$ to 0.7$)$ & 313.3 & 126.7 & 11.3 \\
\hline 33 & 1560 & $-1.3(-2.2$ to -0.4$)$ & 325.8 & 139.3 & 11.8 \\
\hline
\end{tabular}


Table 3 |Long term variability of diastolic blood pressure for those receiving dual treatment; calculated from difference from on treatment baseline measurement $80 \mathrm{~mm} \mathrm{Hg}$ (SD 10) to each subsequent time point

\begin{tabular}{|c|c|c|c|c|c|}
\hline \multirow[b]{2}{*}{ Time (months) } & \multirow[b]{2}{*}{ No of patients } & \multicolumn{2}{|c|}{ Difference from baseline $(\mathrm{mm} \mathrm{Hg})$} & \multirow{2}{*}{$\begin{array}{l}\text { Long term variance* } \\
\qquad(\mathrm{mm} \mathrm{Hg})\end{array}$} & \multirow{2}{*}{$\begin{array}{l}\text { Long term SD } \dagger \\
\quad(\mathrm{mm} \mathrm{Hg})\end{array}$} \\
\hline & & Mean $(95 \% \mathrm{Cl})$ & Variance & & \\
\hline 3 & 1670 & $0.2(-0.2$ to 0.6$)$ & 73.6 & 7.2 & 2.7 \\
\hline 6 & 1637 & $-0.5(-0.9$ to -0.04$)$ & 79.7 & 13.3 & 3.6 \\
\hline 9 & 1644 & $-0.9(-1.3$ to -0.4$)$ & 90.9 & 24.5 & 4.9 \\
\hline 15 & 1623 & $-0.5(-1.1$ to -0.1$)$ & 93.1 & 26.7 & 5.1 \\
\hline 21 & 1612 & $-1.0(-1.5$ to -0.5$)$ & 101.8 & 35.4 & 5.9 \\
\hline 27 & 1584 & $-1.0(-1.5$ to -0.5$)$ & 108.3 & 41.9 & 6.5 \\
\hline 33 & 1560 & $-1.6(-2.1$ to -1.0$)$ & 109.9 & 43.5 & 6.6 \\
\hline
\end{tabular}

*Estimated by subtracting twice short term variance $(33.2 \mathrm{~mm} \mathrm{Hg})$ from variance of difference.

$\ddagger$ Square root of long term variance.

Diastolic blood pressure - The mean blood pressure did not change over time (table 3). As for systolic blood pressure, however, the variability of difference in diastolic blood pressure from baseline increased with the duration of follow-up (table 3 and fig 2). The short term variance was estimated to be $33.2 \mathrm{~mm} \mathrm{Hg}^{2}$ (that is, $\mathrm{SD}$ $5.8 \mathrm{~mm} \mathrm{Hg}$ ). Long term variability increased over the 30 months from an SD of $2.7 \mathrm{~mm} \mathrm{Hg}$ at three months to $6.6 \mathrm{~mm} \mathrm{Hg}$ at 33 months.

\section{Probability of observed increases in blood pressure reflecting true treatment failures}

Tables 4 and 5 show the probabilities that a threshold systolic of $140 \mathrm{~mm} \mathrm{Hg}$ or diastolic of $90 \mathrm{~mm} \mathrm{Hg}$ in a treated patient actually represents a true failure of treatment. Findings are shown for monitoring intervals of between three and 33 months after the start of treatment.

We estimated the probabilities in table 4 using the natural log of measurements of systolic blood pressure to normalise the data, assuming no change in the underlying mean blood pressure of the group and a true blood pressure of either 120 or $130 \mathrm{~mm} \mathrm{Hg}$ at baseline. As such they are the probabilities that an observed increase of 10 or $20 \mathrm{~mm} \mathrm{Hg}$ from a true baseline systolic blood pressure is in fact a true increase of 10 or $20 \mathrm{~mm} \mathrm{Hg}$. For example, suppose that an increase of $20 \mathrm{~mm} \mathrm{Hg}$ in the systolic blood pressure is considered as a "signal" for altering treatment. A patient with a baseline measurement of $120 \mathrm{~mm} \mathrm{Hg}$ monitored at six months has a $0.02 \%$ probability of the measurement truly reaching $140 \mathrm{~mm} \mathrm{Hg}$ or above. However, $3.4 \%$ of individuals would record blood pressure levels of $140 \mathrm{~mm} \mathrm{Hg}$ or above at six months, meaning that for every one true positive result (that is, a true increase of $20 \mathrm{~mm} \mathrm{Hg}$ ) there would be more than 200 other individuals who had an apparent $20 \mathrm{~mm} \mathrm{Hg}$ increase in systolic blood pressure that was caused solely by measurement error.

Likewise, we estimated the probabilities in table 5 assuming no change in the underlying mean diastolic blood pressure of the group and a true blood pressure of either 85 or $90 \mathrm{~mm} \mathrm{Hg}$ at baseline. They represent the probability of an observed increase being a true

Table 4 | Estimated number of true positive and false positive measurements of systolic blood pressure over threshold of $140 \mathrm{~mm} \mathrm{Hg}$ from on treatment baseline "true" measurement of $120 \mathrm{~mm} \mathrm{Hg}$ or $130 \mathrm{~mm} \mathrm{Hg}$

True baseline measurement and time interval between on treatment baseline and follow-up measurements (months)

$120 \mathrm{~mm} \mathrm{Hg}$

\begin{tabular}{|c|c|c|c|}
\hline 3 & 0.0000008 & $2.3(0.000008+2.3)$ & $>1000000$ \\
\hline 6 & 0.02 & $3.4(0.01+3.4)$ & $>200$ \\
\hline 9 & 1.2 & $6.0(0.7+5.3)$ & 7.2 \\
\hline 15 & 1.6 & $6.6(1.0+5.5)$ & 5.3 \\
\hline 21 & 2.6 & $7.5(1.7+5.8)$ & 3.4 \\
\hline 27 & 3.2 & $8.0(2.1+6.0)$ & 2.9 \\
\hline 33 & 3.8 & $8.6(2.5+6.1)$ & 2.4 \\
\hline \multicolumn{4}{|c|}{$130 \mathrm{~mm} \mathrm{Hg}$} \\
\hline 3 & 0.3 & $16.8(0.2+16.6)$ & 93 \\
\hline 6 & 4.6 & $19.0(2.7+16.3)$ & 6.0 \\
\hline 9 & 13.8 & $22.7(9.3+13.5)$ & 1.5 \\
\hline 15 & 15.3 & $23.4(10.4+13.0)$ & 1.3 \\
\hline 21 & 17.5 & $24.5(12.2+12.2)$ & 1.0 \\
\hline 27 & 18.6 & $25.0(13.1+11.9)$ & 0.9 \\
\hline 33 & 19.7 & $25.6(14.1+11.5)$ & 0.8 \\
\hline
\end{tabular}

*"Positive" test is increase in blood pressure above threshold.
"Observed" positive* test as \% of all measurements (true positive+false positive)
Ratio of false positive tests to true positive tests 
increase of 5 or $10 \mathrm{~mm} \mathrm{Hg}$ from the true baseline measurement. Again, by way of example, suppose that an increase of $10 \mathrm{~mm} \mathrm{Hg}$ is considered a "signal" for altering treatment in a patient with a true baseline measurement of $80 \mathrm{~mm} \mathrm{Hg}$. If the patient is monitored at six months there is a $0.3 \%$ probability of the measurement truly reaching $90 \mathrm{~mm} \mathrm{Hg}$ or over. Measurements taken at this time interval would yield an observed positive result in $7.2 \%$ of individuals, meaning that for every one true positive result (that is, a true increase of $10 \mathrm{~mm} \mathrm{Hg}$ ) there would be 39 individuals falsely interpreted as having a $10 \mathrm{~mm} \mathrm{Hg}$ increase in diastolic blood pressure.

The findings in tables 4 and 5 were not substantively different in sensitivity analyses in which we incorporated small annual rises in average population blood pressure $(1.0 \mathrm{~mm} \mathrm{Hg}$ per year for systolic and $0.5 \mathrm{~mm} \mathrm{Hg}$ per year for diastolic). Likewise, in analyses based on mixed models we found no substantial differences in interpretation of the resultant true positive/ false positive tables (tables 4 and 5).

\section{DISCUSSION}

It is usual practice for patients on blood pressure lowering drugs to have their prescription renewed or drugs altered on the basis of blood pressure measurements and clinical review every six months or so. ${ }^{15-17}$ Our results provide little evidence to support the modification of blood pressure management on the basis of measurements made at this interval. If the true on treatment diastolic blood pressure was initially $80 \mathrm{~mm} \mathrm{Hg}$ then $5.8 \%$ of patients would be observed three months later to have $\mathrm{a} \geq 10 \mathrm{~mm} \mathrm{Hg}$ increase to $90 \mathrm{~mm} \mathrm{Hg}$ or over. This would reflect more than 1000 false positives for every true increase, and in nearly all patients in whom treatment was identified as failing the apparently high blood pressure levels would reflect only measurement error. If the true on treatment diastolic blood pressure was $85 \mathrm{~mm} \mathrm{Hg}$ instead then $21.6 \%$ of patients would be observed to have a $\geq 5 \mathrm{~mm} \mathrm{Hg}$ increase to $90 \mathrm{~mm} \mathrm{Hg}$ or over. A much greater proportion of these observations would reflect real increases in blood pressure but there would still be about 11 false positives for every true increase.

It is clear from these data that a single careful blood pressure measurement taken a few months after the start of treatment is not useful for monitoring. The progressive increase over time in the long term variability of measurements between individuals means that an observed change in blood pressure was more likely to reflect a true change in blood pressure with an increase in the time between the start of treatment and follow-up monitoring. This effect was largely driven by the number of true positives increasing with the time interval, while the number of false positives remained fairly constant. The probability that an apparent increase in blood pressure was a true increase rather than a false positive, however, was still not much better than $50 \%$ if the first monitoring interval was left until nearly two years after the start of monitoring.

These data suggest that having accurate measurements of blood pressure at intervals longer than every six months is probably more useful for monitoring patients receiving antihypertensive drugs than the current practice of a clinic measurement every six months. There are several possible strategies for improving the effectiveness of monitoring that need careful quantitative assessment. The chance of detecting true increases in blood pressure would be increased if an abnormal measurement was used as a signal for making a series of repeat measurements at short time intervals. Likewise, having a more accurate estimate of blood pressure at baseline and follow-up would minimise short term variability and increase the capacity to separate true

Table 5 |Estimated number of true positive and false positive measurements of diastolic blood pressure over threshold of $90 \mathrm{~mm} \mathrm{Hg}$ from baseline measurement of 80 or $85 \mathrm{~mm} \mathrm{Hg}$

\begin{tabular}{|c|c|c|c|}
\hline $\begin{array}{l}\text { True baseline measurement and time } \\
\text { interval between on treatment baseline } \\
\text { and follow-up measurements (months) }\end{array}$ & $\begin{array}{c}\% \text { of all measurements truly } \\
\geq 90 \mathrm{~mm} \mathrm{Hg}\end{array}$ & $\begin{array}{l}\text { "Observed" positive* test as } \% \text { of all } \\
\text { measurements (true positive+false } \\
\text { positive) }\end{array}$ & $\begin{array}{l}\text { Ratio of false positive } \\
\text { tests to true positive } \\
\text { tests }\end{array}$ \\
\hline \multicolumn{4}{|l|}{$80 \mathrm{~mm} \mathrm{Hg}$} \\
\hline 3 & 0.01 & $5.8(0.005+5.8)$ & $>1000$ \\
\hline 6 & 0.3 & $7.2(0.2+7.0)$ & 39 \\
\hline 9 & 2.2 & $9.4(1.3+8.1)$ & 6.0 \\
\hline 15 & 2.7 & $9.9(1.7+8.2)$ & 4.9 \\
\hline 21 & 4.6 & $11.3(3.0+8.3)$ & 2.7 \\
\hline 27 & 6.1 & $12.4(4.1+8.3)$ & 2.0 \\
\hline 33 & 6.5 & $12.7(4.4+8.3)$ & 1.9 \\
\hline \multicolumn{4}{|l|}{$85 \mathrm{~mm} \mathrm{Hg}$} \\
\hline 3 & 3.1 & $21.6(1.8+19.8)$ & 11 \\
\hline 6 & 8.5 & $23.2(5.2+18.0)$ & 3.5 \\
\hline 9 & 15.6 & $25.5(10.3+15.2)$ & 1.5 \\
\hline 15 & 16.7 & $26.0(11.2+14.8)$ & 1.3 \\
\hline 21 & 20.0 & $27.3(13.9+13.4)$ & 1.0 \\
\hline 27 & 22.0 & $28.2(15.6+12.6)$ & 0.8 \\
\hline 33 & 22.4 & $28.4(16.0+12.4)$ & 0.8 \\
\hline
\end{tabular}




\section{WHAT IS ALREADY KNOWN ON THIS TOPIC}

Long term monitoring of patients receiving blood pressure lowering drugs is common clinical practice and recommended by guidelines

Individuals' blood pressures vary considerably from day to day, making it difficult to measure the true level

Assessments of treatment efficacy based on noisy measurements might be misleading

\section{WHAT THIS STUDY ADDS}

Recommended monitoring strategies are poor methods for detecting response to blood pressure lowering drug treatment

Guidelines for the management of blood pressure should include evidence based recommendations about monitoring strategies in addition to providing advice about the choice of treatment clinicians to better interpret the meaning of observed increases in blood pressure. For example, if clinicians and patients can be provided with information about the probability that an observed rise is a true rise it would help them to make better decisions about management and avoid a cycle of unnecessary adjustments to treatment and undesirable fluctuations in blood pressure. Such a "ping pong" effect has been observed with the adjustment of warfarin treatment in response to the international normalised ratio (INR) ${ }^{423}$ and might be a problem for many people taking blood pressure lowering drugs.

Follow-up visits and blood pressure monitoring are also used to assess and enhance adherence to treatment. Clearly the observed follow-up blood pressure is going to be a poor indicator of adherence for the same reason that it is a poor indicator of response to treatment, and monitoring prescription records or sensitively questioning patients will probably provide a better assessment of adherence. ${ }^{24}$

\section{Conclusion}

We have shown that the probability of correctly identifying true increases in blood pressure of moderate magnitude using a typical monitoring regimen is poor, with a large proportion of observed increases in blood pressure being false positives. Monitoring at shorter time intervals increases the probability of identifying false positive increases in blood pressure attributable to short term within person variability of blood pressure. Longer intervals between measurements increase the probability that an observed increase in blood pressure is real, but the capacity of monitoring to distinguish true increases in blood pressure is poor even if monitoring is left for several years. Clinicians need better information about the value of different monitoring strategies, and future evidence based monitoring guidelines would be invaluable.

Contributors: $\mathrm{LI}$ conceived the study and is guarantor. All authors contributed to the ideas and writing.

Funding: This study was funded by the Australian National Health and Medical Research Council Program, grants 402764 and 358395. All of the researchers involved in this project are independent of the funding body (Australian National Health and Medical Research Council). PROGRESS was funded by grants from Servier, the Health Research Council of New Zealand, and the National Health and Medical Research Council of Australia. The study was designed, conducted, analysed, and interpreted by the investigators independently of all sponsors. Competing interests: $B N$ has received honoraria from Servier for speaking at scientific meetings. Servier provide research support for the ADVANCE trial of which BN is a management committee member.

Ethical approval: Not required.

1 Blood Pressure Lowering Treatment Trialists' Collaboration. Effects of different blood-pressure-lowering regimens on major cardiovascular events: results of prospectively-designed overviews of randomised trials. Lancet 2003;362:1527-35.

2 Britt $\mathrm{H}$, Miller G, Charles J, Pan Y, Valenti L, Henderson J, et al General practice activity in Australia 2005-06. Canberra: Australian Institute of Health and Welfare, 2007.

3 Marshall T. Measuring blood pressure: the importance of understanding variation. Brasilian I Hypertens 2005;12:75-82.

4 Glasziou P. How should we adjust treatment? In: Glasziou P, Aronson J, Irwig L, eds. Evidence-based medical monitoring: from principles to practice. Malden: Blackwell Publishing, 2008.

5 Rosner B, Polk BF. The implications of blood pressure variability for clinical and screening purposes. J Chronic Dis 1979;32:451-61. 
6 Glasziou P, Irwig L, Mant D. Monitoring in chronic disease: a rational approach. BMJ 2005;330:644-8.

7 PROGRESS Collaborative group. Randomised trial of a perindoprilbased blood-pressure-lowering regimen among 6105 individuals with previous stroke or transient ischaemic attack. Lancet 2001;358:1033-41.

8 Shepard D. Reliability of blood pressure measurements: implications for designing and evaluating programs to control hypertension. J Chronic Dis 1981;34:191-209.

9 Landahl S, Bengtsson C, Sigurdsson JA, Svanborg A, Svardsudd K. Age-related changes in blood pressure. Hypertension 1986;8:1044-9.

10 Goldberg AD, Raftery EB, Cashman PM, Stott FD, Goldberg AD, Raftery EB, et al. Study of untreated hypertensive subjects by means of continuous intra-arterial blood pressure recordings. Br HeartJ 1978;40:656-64.

11 Watson RD, Stallard TJ, Flinn RM, Littler WA. Factors determining direct arterial pressure and its variability in hypertensive man. Hypertension 1980;2:333-41.

12 Mancia G, Ferrari A, Gregorini L, Parai G, Pomidossi G, Bertinieri G, et al. Blood pressure and heart rate variabilities in normotensive and hypertensive human beings. Circ Res 1983;53:96-104.

13 Gordon T, Sorlie P, Kannel WB. Problems in the assessment of blood pressure: the Framingham study. Int I Epidemiol 1976;5:327-34.

14 Progress Management Committee. PROGRESS-perindopril protection against recurrent stroke study characteristics of the study population at baseline. J Hypertenson 1999;17:1647-55.

15 Howard SC, Rothwell PM. Regression dilution of systolic and diastolic blood pressure in patients with established cerebrovascular disease. J Clin Epidemiol 2003;56:1084-91.

16 Mancia G, De Backer G, Dominiczak A, Cifkova R, Fagard R, Germano G, et al. 2007 Guidelines for the management of arterial hypertension: the task force for the management of arterial hypertension of the European Society of Hypertension (ESH) and of the European Society of Cardiology (ESC). J Hypertens 2007;25:1105-87.

17 National Heart Foundation of Australia. Hypertension management guide for doctors 2004. Melbourne: National Heart Foundation, 2003.

18 McManus RJ, Glasziou P, Hayen A, Mant J, Padfield P, Potter J, et al. Blood pressure self monitoring: questions and answers from a national conference. BMJ 2008:a2732.

19 Macaskill P. Control charts and control limits in long-term monitoring. In: Glasziou P, Irwig L, Aronson J, eds. Evidence-based medical monitoring. From principles to practice. Malden: Blackwell Publishing Inc, 2008.

20 Harrison WN, Lancashire RJ, Marshall TP. Variation in recorded blood pressure terminal digit bias in general practice. J Hum Hypertens 2008;22:163-7.

21 Whitworth JA, World Health Organization International Society of Hypertension Writing Group. 2003 World Health Organization (WHO)/International Society of Hypertension (ISH) statement on management of hypertension. J Hypertens 2003;21:1983-92.

22 Williams B, Poulter N, Brown M, Davis M, McInnes G, Potter J, et al. Guidelines for the management of hypertension: report of the fourth working party of the British Hypertension Society, 2004-BHS IV. Hum Hypertens 2004;18:139-85.

23 Lassen JF, Kjeldsen J, Antonsen S, Hyltoft Petersen P, Brandslund I. Interpretation of serial measurements of international normalized ratio for prothrombin times in monitoring oral anticoagulant therapy. Clin Chem 1995;41:1171-6.

24 MacLaughlin EJ, Raehl CL, Treadway AK, Sterling TL, Zoller DP, Bond CA. Assessing medication adherence in the elderly: which tools to use in clinical practice? Drugs Aging 2005;22:231-55.

Accepted: 7 January 2009 